\title{
Factors Associated With Medication Adherence In Elderly Retired Outpatients In São Paulo, Brazil
}

This article was published in the following Dove Press journal: Patient Preference and Adherence

Juliana Martins Ribeiro Valassi'

Nelson Carvas Junior'

Mirian Matsura Shirassu'

Kaleo Eduardo de Paula'

Elena R Atkinson (D) $^{2}$

Marcia Kiyomi Koike $\mathbb{D}^{1,3}$

'Health Sciences Department, Institute for Medical Assistance to State Public Servants, São Paulo, Brazil; ${ }^{2}$ Fundación IDEA, Mexico City, Mexico; ${ }^{3}$ Emergency Medicine Department, Medical School,

University of São Paulo, São Paulo, Brazil

Correspondence: Marcia Kiyomi Koike Programa de Pós-Graduação em Ciências da Saúde. Instituto de Assistência Médica ao Servidor Público Estadual (IAMSPE),

Brasil Av. Ibirapuera, 98I - $2^{\circ}$ andar, Vila

Clementino, São Paulo/SP CEP: 04029-000,

Brazil

Tel +55 II 9 9964-842 I

Email mkkoikel7@gmail.com
Objective: To evaluate medication adherence and associated socioeconomic factors in elderly Brazilians.

Methodology: This observational study was conducted with 159 elderly retired in an outpatient clinic in the city of São Paulo. Treatment adherence was assessed with the questions from the Morisky Green Levine Medication Adherence Questionnaire, and medications were classified using the Anatomical Therapeutic Chemical system. Statistical tests and adjusted Poisson regression models were used to analyze variables.

Results: The study population was mostly female (67.5\%), had an average age of, and took an average of 6.5 medications per day. The most commonly used drugs were agents acting on the renin-angiotensin system $(67.9 \%)$, statins $(62.3 \%)$, antithrombotic agents $(48.4 \%)$, and biguanides $(37.1 \%)$ for the treatment of hypertension $(76.7 \%)$, dyslipidemia $(54.1 \%)$, and diabetes $(47.8 \%)$. The rate of adherence was below $60 \%$ in the groups of participants that were analyzed except for the high household income category, which had a rate of $75.8 \%$. Conclusion: Medication adherence among the elderly was low in all categories except for the high household income category, a relevant finding that will help to understand medication adherence patterns in elderly Brazilians.

Keywords: medication adherence, aged, geriatrics, polypharmacy, drug therapy, socioeconomic factors

\section{Introduction}

Transformative advances in healthcare, especially in pharmacology, have contributed to significantly increased life expectancy worldwide. However, the people for whom these medications are designed do not always consume them in accordance with clinical indications. The elderly make up a population of particular interest in medication adherence research as - in addition to consuming the highest proportion of medication per capita - they are beginning to occupy a more substantial proportion of the total population. Additionally, older adults with chronic conditions are at a higher risk of suffering damaging health consequences caused by lack of compliance with drug indications. ${ }^{1,2}$ Issues with adherence mainly occur among elderly people who use five or more drugs per day, a situation known as polypharmacy. Recent publications demonstrate that most older adults are unable to take multiple simultaneous prescriptions adequately. ${ }^{3,4}$

Elderly people (above the age of 60) currently make up approximately $14 \%$ of the Brazilian population, and this proportion is projected to increase to almost $30 \%$ 
by $2050 .{ }^{5}$ In addition to an increase in this population, medication use in this country is expected to increase, meaning that medication adherence is, therefore, a significant research topic for Brazil. The nation's socialized public healthcare system provides an additional incentive to better understand the factors that impede senior citizens with chronic disease from taking their medications as indicated, as lack of adherence can increase healthcare costs. ${ }^{1,6,7}$ This document will use the World Health Organization's definition of adherence, which is: "the extent to which a person's behavior-taking medication, following a diet, and/or executing lifestyle changes - corresponds with agreed recommendations from a health care provider." 8

An observational study by Uchmanowicz ${ }^{9}$ using this scale found higher rates of adherence in participants with higher educational achievement and family support, indicating a possible relationship between socioeconomic factors and medication, albeit one that is not widely studied. ${ }^{10}$ Previous studies on medication adherence in elderly people in developing countries, especially in the context of polypharmacy, have previously incorporated socioeconomic variables. However, very few studies explicitly state that this is the primary motive for the study. Another issue is the lack of ability to compare adherence findings between different countries and regions. Specific instruments - such as the Anatomical Therapeutic Chemistry (ATC) ${ }^{11}$ classification and the Morisky Green Levine Medication Adherence Questionnaire (MGLQ) ${ }^{12}$ - have been validated to measure medication use and adherence, respectively. The MGLQ is one of the most widely used questionnaires in Brazilian research on medication adherence ${ }^{13,14}$ and was selected for this study for this reason and also because it provides standardized results to compare adherence across cultures and countries. Most studies on adherence in Brazil are not published in English, and the MGLQ will allow for our results to reach a wider international audience.

Brazil has numerous medical, social, and economic reasons for requiring a study on medication adherence in the elderly. The nation is a middle-income country with high levels of inequality — especially among older adults that is going through a demographic transition. Brazil is also one of the countries with the highest rates of polypharmacy in the world, along with the United States, Sweden, India, the United Kingdom, and China. ${ }^{15,16}$ Chronic diseases are an increasing concern in Brazil, and suboptimal medication adherence is thought to be impeding chronic disease control. The socialized public health system still lacks comprehensive public policy on medication distribution. ${ }^{2}$ Accordingly, this study was designed to provide evidence on medication adherence and related socioeconomic factors among elderly retirees in an outpatient clinic in São Paulo. It was conducted in the city of São Paulo, as it is the largest and most populated city in the country and also has a large population of elderly residents.

\section{Methods}

\section{Study Design, Setting, And Population}

This cross-sectional study was carried out in elderly retiree outpatients of the cardiology and endocrinology departments at a public hospital in São Paulo. These two outpatient clinics were chosen because of their high volume of geriatric patients with chronic conditions and without cognitive decline or severe acute disease. The clinics provided enough patients for the sample size (159 patients) to be representative of the broader population of older retired adults in São Paulo. Data collection occurred between June 2016 and July 2017.

All elderly patients requesting medical attention at these clinics during the data collection period were approached and asked if they wished to participate in the study. If the patient expressed interest, the study design and purpose was explained in plain language, and the patient signed an informed consent form to agree to their official participation in the research study. Inclusion criteria included being a retired adult between the age of 60 and 75 and taking at least two medications per day. Retirement was defined as receiving a monthly pension from the government; in Brazil, men can receive a government pension once they turn 65 and women, once they turn 60 , or any individual can receive a pension for working a stipulated number of years or for work-related injuries/disabilities. The age limit to define the elderly was set per World Health Organization guidelines, which define elderly people as individuals over the age of 60 in lesserdeveloped regions. ${ }^{6}$ An estimated $77 \%$ of Brazilians with dementia have not been diagnosed, ${ }^{17,18}$ and therefore, all patients over the age of 75 were excluded. This was to avoid ethical issues and to avoid introducing recall bias into the study. The only other exclusion criterion was insufficient mental capacity to respond to questionnaire items. To ensure the complete absence of memory issues, research personnel also administered the Mini-Mental State Examination (MMSE), ${ }^{19}$ an easy-to-administer and 
widely-used instrument. The MMSE is a screening test for possible cognitive decline, in which a score of 24 or lower suggests cognitive decline. ${ }^{19}$ In this study, two potential participants had a score below 25 and were therefore excluded.

\section{Questionnaire: General Information}

This study used the MGLQ and ATC instruments: both questionnaires had been previously translated into Portuguese and validated. A pharmacy student and two nurses administered the questionnaires in face-to-face interviews in Portuguese in approximately $40 \mathrm{~min}$ sessions on the day of the respective patient's appointment. All patient-reported information was corroborated with patient files to avoid bias.

Socioeconomic variables were divided into categories: marital status was divided into married or other (unmarried, divorced, or widowed); educational level was divided into low level of schooling (illiterate or incomplete elementary school), some schooling (complete elementary school or incomplete secondary school), and complete basic education (complete secondary education or above); housing was divided into other (inherited house, renting, or living with children) and home-owner; reason for retirement was divided into retirement by age, time of service, or disability; retirement times were dichotomized as fewer than 10 years or over 10 years. Household income was divided into low income (below two minimum monthly salaries) and high income (above two minimum monthly salaries). As a reference, the minimum monthly salary in 2017 was BRL 937, or approximately USD 250. Brazilians are generally uncomfortable reporting their annual income to strangers and this was a division that most participants were familiar with and comfortable with reporting.

\section{Morisky, Green And Levine Medication Adherence Questionnaire}

Adherence to drug treatment was assessed using the questions contained in the MGLQ, a test developed in the United States and validated for the Portuguese language. The test is easy to understand and consists of four yes-orno questions that identify attitudes towards drug therapy and behaviors involved in taking medication. Each "yes" receives a score of zero (0), and each "no" receives a score of one (1). If all the answers are "no," the score is 4 , and if all the answers are "yes," it is 0 . In our research, participants with a score between 0 and 2 points were classified as "not adherent" and participants with a score of 3 or 4 points were classified as "adherent."

\section{Anatomical Therapeutic Chemical Classification System}

We used the ATC to analyze the medications our study participants used. With the ATC methodology, drugs are divided into groups at their respective sub-levels based on their mechanisms of action, chemical properties, therapeutic actions, and kinetic and dynamics classifications. The ATC's standardization allows for comparable statistical studies, which then allows for improved comparations and measurements in drug development and utilization. ${ }^{13}$

\section{Sample Size}

The sample size was calculated with the 6th edition of the EpiInfo program using statistics on the number of retirees in São Paulo (53.7\%), older adults with dementia (13\%), and individuals in polypharmacy regimens. These percentages were used to calculate the proportion of retirees both in treatment and in follow-up, subtracting the estimated number of retirees with dementia. The formula was applied to the final value and multiplied by 1.18 , estimating a refusal rate of $10 \%$ and an incompletion rate of $5 \%$. A total of 167 elderly outpatients were approached, of which eight patients were excluded for not fulfilling inclusion/exclusion criteria or for filling out the questionnaires incorrectly. Therefore, the final sample size was 159 participants.

\section{Statistical Analysis}

The data were first described with descriptive statistics, including mean and standard deviation, absolute numbers, and relative percentages for quantitative variables. A Shapiro-Wilk test and Levene test were run to verify assumptions of normal distribution and homogeneity of variances, both for age $(\mathrm{W}=0.961 ; \mathrm{p}<0.001 / \mathrm{F}(49)=0.901 ; \mathrm{p}=0.645)$ and for the number of medications used $(\mathrm{W}=0.959$; $\mathrm{P}=0.0001 / \mathrm{F}(49)=1.047 ; \mathrm{P}=0.873)$. A Mann-Whitney test was used to compare ages and numbers of medications. Pearson Chi-square tests were used to compare marital status, education levels, household income, housing, retirement time, and retirement type between the sexes. The association between the variables and adherence to medication use on the MGLQ was tested using Poisson regression models adjusted with robust variance. All analyses were performed in the version 3.4.2 of $\mathrm{R}$ using the prevalence and sandwich 
packages. The level of significance adopted for all analyses was $\mathrm{p}<0.05$.

\section{Ethics}

The Research Ethics Committee of IAMSPE approved the study, with reference number 1.598.277. All participants received a clear, plain-language summary of the study design, benefits, and risks and then signed voluntary informed consent forms. As this study was purely observational and questionnaire-based, the risk to participants was considered low.

\section{Results}

A total of 167 elderly outpatients were approached, of which two patients refused participation and eight patients did not fulfill inclusion/exclusion criteria or fill out the questionnaires correctly. Therefore, the total final sample size was 159 participants. The sample was predominantly female (68.5\%), highly educated (50.3\%), had above-average income $(60.5 \%)$, and were home-owners (95\%). The average age of the participants was $68.30 \pm 4.0$ years, $80 \%$ were retired after meeting the minimum number of years worked, and $67 \%$ had been retired for over ten years (Table 1).

The most common chronic diseases were: systemic arterial hypertension (76.7\%), dyslipidemias (54.1\%), diabetes/hyperglycemia (47.8\%), and gastro-esophageal reflux disease (GERD, 38\%), as shown in Table 2. Table 3 presents the medicines that the elderly used, divided into generic denominations of the ATC classification. The most commonly used agents were those that act on the reninangiotensin system (67.9\%), inhibitors of the enzyme 3hydroxy-3-methyl-glutaryl-CoA reductase - also known as statins - (62.3\%), antithrombotic agents (48.4\%), medicines for the treatment of peptic ulcers (36.5\%), and biguanides (37.1\%). Many of the participants were on polypharmacy regimens, taking an average of 6.5 medications per day.

The results of adherence measured with the MGLQ and analyzed with Poisson regression analysis are presented in Table 4 . The medication adherence rate was below $60 \%$ in all of the socioeconomic categories that were analyzed,

Table I General Characteristics Of The Sample By Patient Gender

\begin{tabular}{|c|c|c|c|c|}
\hline Variables & Female $(n=109)$ & Male $(n=50)$ & Total $(n=159)$ & P Value \\
\hline Age (years) & $68.3 \pm 4.0$ & $684 \pm 4.2$ & $68.3 \pm 4.0$ & 0.859 \\
\hline Medications used per day & $6.5 \pm 2.7$ & $6.4 \pm 2.7$ & $6.5 \pm 2.7$ & 0.952 \\
\hline Variables & $\mathbf{N}(\%)$ & $\mathbf{N}(\%)$ & $\mathbf{N}(\%)$ & $P$ Value \\
\hline $\begin{array}{l}\text { Marital status } \\
\text { Married } \\
\text { Others }\end{array}$ & $\begin{array}{l}58(53.2) \\
51(46.8)\end{array}$ & $\begin{array}{l}44(88.0) \\
6(12.0)\end{array}$ & $\begin{array}{l}102(64.2) \\
57(35.8)\end{array}$ & $<0.001$ \\
\hline $\begin{array}{l}\text { Educational level } \\
\text { Low } \\
\text { Medium } \\
\text { High }\end{array}$ & $\begin{array}{l}33(30.3) \\
22(20.2) \\
54(49.5)\end{array}$ & $\begin{array}{l}13(26) \\
11(22) \\
26(52)\end{array}$ & $\begin{array}{l}46(28.9) \\
33(20.8) \\
80(50.3)\end{array}$ & 0.855 \\
\hline $\begin{array}{l}\text { Household income } \\
\text { Below two minimum salaries } \\
\text { Above two minimum salaries }\end{array}$ & $\begin{array}{l}47(42.6) \\
62(57.4)\end{array}$ & $\begin{array}{l}17(32.7) \\
33(67.3)\end{array}$ & $\begin{array}{l}64(39.5) \\
95(60.5)\end{array}$ & 0.315 \\
\hline $\begin{array}{l}\text { Type of residence } \\
\text { Owner-occupied } \\
\text { Others }\end{array}$ & $\begin{array}{l}105(96.3) \\
4(3.7)\end{array}$ & $\begin{array}{l}46(92.0) \\
4(8.0)\end{array}$ & $\begin{array}{l}|5|(95.0) \\
8(5.0)\end{array}$ & 0.442 \\
\hline $\begin{array}{l}\text { Retirement time } \\
\text { Less than ten years } \\
\text { More than ten years }\end{array}$ & $\begin{array}{l}67(61.5) \\
42(38.5)\end{array}$ & $\begin{array}{l}26(52.0) \\
24(48.0)\end{array}$ & $\begin{array}{l}93(58.5) \\
66(41.5)\end{array}$ & $0.34 I$ \\
\hline $\begin{array}{l}\text { Type of retirement } \\
\text { Age } \\
\text { Number of years worked } \\
\text { Disability/other }\end{array}$ & $\begin{array}{l}18(16.5) \\
80(73.4) \\
11(10.1)\end{array}$ & $\begin{array}{l}4(8.0) \\
42(84.0) \\
4(8.0)\end{array}$ & $\begin{array}{l}22(13.8) \\
122(76.7) \\
15(9.4)\end{array}$ & 0.293 \\
\hline
\end{tabular}


Table 2 Frequency Distribution Of Morbidities By Patient Gender

\begin{tabular}{|c|c|c|c|}
\hline Morbidity & $\begin{array}{l}\text { Female }(n=109) \\
n(\%)\end{array}$ & $\begin{array}{l}\text { Male }(n=50) \\
n(\%)\end{array}$ & $\begin{array}{l}\text { Total }(n=159) \\
n(\%)\end{array}$ \\
\hline Systemic arterial hypertension & $82(75.2)$ & $40(80.0)$ & $122(76.7)$ \\
\hline Dyslipidemia & $62(56.9)$ & $24(48.0)$ & $86(54.1)$ \\
\hline Diabetes mellitus & $48(44.0)$ & $28(56.0)$ & $76(47.8)$ \\
\hline GERD & $16(14.7)$ & $6(12.0)$ & $22(38.0)$ \\
\hline Hypothyroidism & $36(33.0)$ & $8(16.0)$ & $44(27.7)$ \\
\hline Arthrosis & $27(24.8)$ & $12(24.0)$ & $39(24.5)$ \\
\hline Arrhythmia & $6(5.5)$ & $10(20.0)$ & $16(10.1)$ \\
\hline Depression & $13(11.9)$ & $3(6.0)$ & $16(10.1)$ \\
\hline Coronary insufficiency & $11(10.1)$ & $5(10.0)$ & $16(10.1)$ \\
\hline Osteopenia & $14(12.8)$ & $I(2.0)$ & $13(8.2)$ \\
\hline Arthritis & $9(8.3)$ & $2(4.0)$ & II (6.9) \\
\hline Hepatic steatosis & $8(7.3)$ & I (2.0) & $9(5.7)$ \\
\hline Gastritis & $9(8.3)$ & $0(0)$ & $9(5.7)$ \\
\hline Glaucoma & $7(6.4)$ & $2(4.0)$ & $9(5.7)$ \\
\hline Asthma & $6(5.5)$ & $2(4.0)$ & $8(5.0)$ \\
\hline Coronary arterial disease & $6(5.5)$ & $2(4.0)$ & $8(5.0)$ \\
\hline Osteoporosis & $7(6.4)$ & I (2.0) & $8(5.0)$ \\
\hline Cataracts & $5(4.6)$ & $2(4.0)$ & $7(4.4)$ \\
\hline Chronic atrial fibrillation & $6(5.5)$ & I (2.0) & $7(4.4)$ \\
\hline Chronic renal insufficiency & $4(3.7)$ & $3(6.0)$ & $7(4.4)$ \\
\hline Prostatic hyperplasia & I (0.9) & $5(10.0)$ & $6(3.8)$ \\
\hline Hyperthyroidism & $3(2.8)$ & I (2.0) & $4(2.5)$ \\
\hline Lower back pain & $3(2.8)$ & I (2.0) & $4(2.5)$ \\
\hline Varicose veins & $4(3.7)$ & $0(0)$ & $4(2.5)$ \\
\hline Cardiac valvulopathy & $2(1.8)$ & $2(4.0)$ & $4(2.5)$ \\
\hline Cerebral vascular accident & $3(2.8)$ & $0(0)$ & $3(1.9)$ \\
\hline COPD & $2(1.8)$ & I (2.0) & $3(1.9)$ \\
\hline Labyrinthitis & $3(2.8)$ & $0(0)$ & $3(1.9)$ \\
\hline Alzheimer's disease & I (0.9) & I (2.0) & $2(1.3)$ \\
\hline Ischemic stroke & I (0.9) & I (2.0) & $2(1.3)$ \\
\hline Gout & I (0.9) & I (2.0) & $2(1.3)$ \\
\hline Inguinal hernia & I (0.9) & I (2.0) & $2(1.3)$ \\
\hline Hypoparathyroidism & $2(1.8)$ & $0(0)$ & $2(1.3)$ \\
\hline Gall stones & $\mathrm{I}(0.9)$ & $0(0)$ & $\mathrm{I}(0.6)$ \\
\hline Bipolar Disorder & I (0.9) & $0(0)$ & I $(0.6)$ \\
\hline Diverticulitis & I (0.9) & $0(0)$ & I $(0.6)$ \\
\hline Epilepsy & $0(0)$ & I (2.0) & $\mathrm{I}(0.6)$ \\
\hline Congestive cardiac insufficiency & $\mathrm{I}(0.9)$ & $0(0)$ & $\mathrm{I}(0.6)$ \\
\hline Gastric reflux & I (0.9) & $0(0)$ & $\mathrm{I}(0.6)$ \\
\hline
\end{tabular}

Abbreviations: GERD, gastroesophageal reflux disease; COPD, chronic obstructive pulmonary disease.

with no statistically significant difference between groups except in the high-household-income cohort, where the prevalence of adherence was $75.8 \%$.

\section{Discussion}

This study evaluated the level of medication adherence among retired elderly participants and related socioeconomic factors in a public outpatient clinic in the city of São Paulo.
The study population mostly consisted of women with high levels of education who were homeowners with a household income considered high for elderly Brazilians. The mean age of the participants was 68 , and most had retired after having worked the required number of years. As this research was carried out in a large urban center, it contrasts with other studies in rural areas, where elderly residents live in more varied socioeconomic conditions. 
Table 3 Distribution Of Frequencies Of Medications Used Under Generic Names - Anatomical Therapeutic Chemistry Classification

\begin{tabular}{|c|c|c|}
\hline $\begin{array}{l}\text { Anatomical Therapeutic Chemistry } \\
\text { Classification }\end{array}$ & $\mathbf{N}$ & (\%) \\
\hline A02B - Medications for the treatment of peptic ulcers & 58 & 36.5 \\
\hline A03 - Propulsive agents & 10 & 6.3 \\
\hline AIOA - Insulin and analogs & 27 & 17 \\
\hline AIOBA - Biguanides & 59 & 37.1 \\
\hline AIOBB - Sulfonylureas & 40 & 25.2 \\
\hline AIOBG - Thiazolidinediones & 14 & 8.8 \\
\hline BOI - Antithrombotic agents & 77 & 48.4 \\
\hline COIB - Antiarrhythmics & 11 & 6.9 \\
\hline COID - Vasodilators used in heart disease & 17 & 10.7 \\
\hline COIE - Other cardiac preparations & 2 & 1.3 \\
\hline C02A - Central acting alpha-adrenergic antagonist & 2 & 1.3 \\
\hline C02C - Peripheral alpha-adrenergic antagonist & 2 & 1.3 \\
\hline C02D - Direct vasodilators & 7 & 4.4 \\
\hline C03A - Thiazide diuretics & 45 & 28.3 \\
\hline C03C - Loop diuretics & 16 & 10.1 \\
\hline C03D - Potassium-sparing diuretics & 6 & 3.8 \\
\hline C07 - Beta-blocker agents & 66 & 41.5 \\
\hline C08 - Calcium channel blockers & 31 & 19.5 \\
\hline C09-Agents acting on the renin-angiotensin system & 107 & 67.3 \\
\hline $\begin{array}{l}\text { CIOAA - 3-hydroxy-3-methyl-glutaryl-CoA reductase } \\
\text { inhibitors (statins) }\end{array}$ & 99 & 62.3 \\
\hline CIOAB - Fibrates & 2 & 1.3 \\
\hline H02 - Corticosteroids for systemic use & 2 & 1.3 \\
\hline $\mathrm{H} 03 \mathrm{~A}$ - Thyroid hormones & 46 & 28.9 \\
\hline $\begin{array}{l}\text { MOIA - Non-steroidal anti-inflammatory and anti- } \\
\text { rheumatic agents }\end{array}$ & 7 & 4.4 \\
\hline M03BX - Other central-acting agents & 3 & 1.9 \\
\hline N02 - Analgesics & 4 & 2.5 \\
\hline N02A - Opioids & 1 & 0.6 \\
\hline N02B - Other analgesics and antipyretics & 18 & 11.3 \\
\hline N03AE - Benzodiazepines & 1 & 0.6 \\
\hline N05A - Antipsychotics & 4 & 2.5 \\
\hline N05BA - Benzodiazepines & I & 0.6 \\
\hline N05C - Hypnotics and sedatives & I & 0.6 \\
\hline N06A - Antidepressants & 5 & 3.1 \\
\hline N06AB - Selective serotonin reuptake inhibitors & 17 & 10.7 \\
\hline SOIE - Antiglaucoma and miotic preparations & 5 & 3.1 \\
\hline
\end{tabular}

Previous publications in the literature have suggested a possible relationship between low adherence and socioeconomic factors. One study carried out in 934 elderly residents of the Brazilian state of Goiás (predominantly widows and low-income earners) found a prevalence of adherence of $24 \%$ for those on polypharmacy regimens. Another Brazilian study, conducted in primarily lowincome elderly people in the state of Rio Grande do Sul, found a prevalence of low adherence among a third of the 1,598 people interviewed. A third Brazilian study, in the state of Minas Gerais, found that adherence was $47 \%$ in 279 elderly participants, most of whom were low-income women on polypharmacy regimens. ${ }^{7,20,21}$

The most common chronic morbidities in treatment in our study participants were systemic arterial hypertension, dyslipidemia, diabetes mellitus/hyperglycemia, and gastroesophageal reflux disease. This distribution of chronic conditions is in line with Stopa's ${ }^{22}$ findings: a considerable increase in the incidence of these pathologies in São Paulo from 2003 to 2015 with low adherence to recommended behavioral changes. It is widely known that both behavioral changes (improvements in diet and lifestyle) and pharmacological treatments are necessary to prevent and control chronic disease. However, Brazilians tend to prefer pharmacological treatments, as they are easier to access, have a more evident therapeutic efficacy, and are simpler to take than making lifestyle changes. This difficulty in promoting lifestyle changes has been evidenced by low adherence to non-medication treatments as an auxiliary to pharmacological treatment. ${ }^{20,21,23-30}$

The most used medications in this study, organized by ATC classification, were agents acting on the renin-angiotensin system, statins, antithrombotic agents, and biguanides. These drugs are used to treat the most prevalent diseases among the elderly, such as hypertension, dyslipidemia, and diabetes/hyperglycemia, which are the very same diseases that are predominant in our population. ${ }^{22,23,25-30}$ The ATC classification used in this study is an important contribution to the literature, as the study results are standardized internationally - a rarity in Brazilian publications. Using this classification, we found an average use of 6.5 medications per day, which meets the definition of polypharmacy, a situation also found in other Brazilian and international articles on the subject. 16,25

In our study, the prevalence of adherence measured with the MGLQ questions was below $60 \%$ in all categories, except for those in the high household income category $(75.8 \%)$. The literature considers adherence rates between 40 and $60 \%$ to be low. ${ }^{8,12,31,32}$ Menditto et al. $^{5}$ carried out an exploratory study of 39,000 elderly patients in three European countries using medication registries to calculate non-adherence. The study authors found prevalences of non-adherence to the use of antihyperlipidemic drugs to be $36.87 \%$ in Ireland, $60.93 \%$ in Spain, and $68.44 \%$ in Italy, with general medication adherence rates of $50 \%$ in the three countries. Lee ${ }^{25}$ conducted an observational study of 1,154 (predominantly elderly) hypertensive individuals in Hong Kong, finding low or 
Table 4 Prevalence Of Medication Adherence According To Participant Characteristics

\begin{tabular}{|c|c|c|c|c|}
\hline Variable & $\mathbf{N}$ & Prevalence (\%) & $P$ Value & PR (IC95\%) \\
\hline \multicolumn{5}{|l|}{ Sex } \\
\hline Female & 52 & $47.7(38.4-57.1)$ & & I \\
\hline Male & 23 & $46.0(32.2-59.8)$ & 0.842 & $0.96(0.67-1.38)$ \\
\hline \multicolumn{5}{|l|}{ Educational level } \\
\hline Low & 20 & $43.5(29.2-57.8)$ & & 1 \\
\hline Medium & 14 & $42.4(25.6-59.3)$ & 0.926 & $0.98(0.58-1.63)$ \\
\hline High & 41 & $51.3(40.3-62.2)$ & 0.412 & $1.18(0.80-1.75)$ \\
\hline \multicolumn{5}{|l|}{ Residence } \\
\hline Other & 3 & $37.5(3.4-71.0)$ & & 1 \\
\hline Owner-occupied & 72 & $47.7(39.7-55.6)$ & 0.605 & $1.27(0.5 I-3.16)$ \\
\hline \multicolumn{5}{|l|}{ Household income } \\
\hline Below two minimum salaries & 26 & $41.9(29.7-54.2)$ & & 1 \\
\hline Above 2 minimum salaries & 72 & $75.8(67.2-84.4)$ & 0.249 & I.23 (0.87-I.75) \\
\hline \multicolumn{5}{|l|}{ Retirement time } \\
\hline Up to 10 years & 40 & $43.0(32.9-53.1)$ & & 1 \\
\hline More than 10 years & 35 & $21.1(14.9-27.3)$ & 0.208 & $1.23(0.89-1.7 I)$ \\
\hline \multicolumn{5}{|l|}{ Marital status } \\
\hline Married & 49 & $45.6(32.7-57.7)$ & & 1 \\
\hline Others & 26 & $45.6(32.7-58.5)$ & $0.77 \mid$ & $0.95(0.67-1.35)$ \\
\hline \multicolumn{5}{|l|}{ Type of retirement } \\
\hline By age & 13 & $59.1(38.5-79.6)$ & & 1 \\
\hline By time of service & 57 & $46.7(37.9-55.6)$ & 0.245 & $0.79(0.53-1.18)$ \\
\hline By disability/pension & 5 & $33.3(9.5-57.2)$ & 0.159 & $0.56(0.26-1.25)$ \\
\hline
\end{tabular}

Abbreviations: PR, Prevalence ratio of medication adherence, adjusted by Poisson regression with robust variance; $95 \% \mathrm{Cl}, 95 \%$ confidence intervals.

poor treatment adherence on the Morisky Medication Adherence Scale (MMAS). These studies all show low adherence rates in a variety of countries with different populational indices, socioeconomic conditions, and governing styles. The results show that low adherence among the elderly is a global public health problem in need of effective solutions.

The proportion of low adherence found in our study in almost all of the analyzed categories, except the high-income category, suggests a possible relationship between socioeconomic factors and adherence. During this study, we also observed a lack of drug assistance at the outpatient level. That is, doctors are the only providers who are responsible for advising elderly patients on medication use, and they only have limited office visit hours to provide this patient education. For elderly insulin-dependent diabetic patients in endocrinology outpatient clinics, nurses are responsible for teaching them the correct use of glucometers and insulin application techniques. International literature recommends using a comprehensive and team-based approach (involving other healthcare professionals, such as pharmacists and nurses), as they have positive results on adherence. ${ }^{23-25}$

The role of family support in treatment adherencealthough not evaluated formally in this study-has emerged as a likely mediating factor between physicians and their elderly patients, even those with preserved cognitive ability. As adherence has been found to be higher in older adults with higher household incomes, there may be a relationship between high income and adequate family support. Therefore, professionals could work together with families in all socioeconomic categories to seek solutions for correct medication use. Comprehensive medication support could help avoid the preventable risks that are associated with low adherence and resultant treatment ineffectiveness, such as adverse reactions, hospitalizations, and even deaths. ${ }^{31-35}$ Recent studies suggest that educational programs, monitoring, and gerontological follow-up could be facilitating factors. These, together with family support, could be fruitful areas for new research in elderly patients. ${ }^{7,27-30,32,33,36}$ 
The positive association found in this study between household income and medication adherence is an important advancement in this research field, especially considering the scarcity of Brazilian publications on this topic. As Brazil moves through a demographic transition and gains an increased proportion of older adults, the nation will most likely see an increase in medication consumption in a country that is already known for an above-average prevalence of polypharmacy. Polypharmacy coupled with marked social inequality and high poverty rates among the elderly could contribute to widening both the health and wealth gap in some of Brazil's most vulnerable citizens.

The only significant association found in our study between adherence and patient variables was in income level. We believe that high adherence in the high household income cohort suggests a possible relationship between medication adherence and socioeconomic factors for elderly retirees on polypharmacy regimens. However, this is different from other Brazilian publications as this study was carried out in the biggest city on the continent and with retired government workers and their families. ${ }^{7,11,29}$ The current study found low medication adherence in elderly outpatients across most of the analyzed socioeconomic categories, except in the high household income category. We posit that this is because the Brazilian public healthcare system provides a limited amount of free medications to all residents, but senior citizens with above-average household income have more financial resources to purchase highercost drugs that are sold at private pharmacies. This group has the necessary financial resources to procure these medicines as well as access to other facilitators, such as the probable family support involved in monitoring medication use as part of health care.

Our findings demonstrate the need to implement public policies in the social and health spheres to meet the needs of the elderly population. Most senior citizens are retired and live in predominantly low socioeconomic conditions with probable low medication adherence. Educational programs on how medications work and the importance of taking them correctly should be implemented, with effective participation of pharmacists and nurses. This study sets a precedent for new research on adherence improvement methods, the importance of family participation in this process, and the complexity of the elderly using multiple medications, with its risks of complications and impacts on public health.

We recognize that our study presents several limitations, namely in terms of external validity. The first significant limitation is that we excluded potential participants over the age of 75 from this study. We initially did this to avoid introducing memory bias into the research study and to avoid inadvertently diagnosing dementia, which would have raised severe ethical issues. However, we recognize that this may have limited our study size and the applicability of these results to older geriatric patients; therefore, we recommend that, instead of setting age limits, future studies should apply the MMSE or other similar screening tools. Our study was also limited by the types of patients that we recruited; the endocrine and cardiology outpatient clinics were the only specialties that could provide the volume of eligible patients required for this study's sample size. In addition to limiting the age range and types of conditions, our study was also limited in terms of geographical extension. The results presented here are representative of São Paulo only, and, therefore, may not be an accurate representation of the general Brazilian situation. However, São Paulo is the largest city in South America and has some of the highest standards of living and healthcare coverage in Latin America. Thus, if adherence was low in São Paulo, areas far from major urban centers - where living conditions and healthcare coverage are worse-may see even lower adherence rates. Therefore, while our findings of specific proportions of adherence may not be valid for direct comparison with other cities/states in Brazil, our study exposes a clear need and is a call for more research and interventions on medication adherence in this country.

\section{Conclusion}

Medication adherence was low across all groups of retired senior citizens, except in the group of participants with high household income: a finding that could be key to understanding medication adherence in elderly Brazilians. Our study only focused on elderly residents below the age of 75, and future research could focus on even older geriatric patients, such as those in their $80 \mathrm{~s}, 90 \mathrm{~s}$, or older. Future studies can use our findings on socioeconomic status to focus on understanding and improving adherence, on both public policy and clinical levels.

\section{Author Contributions}

All authors contributed to data analysis, drafting or revising the article, gave final approval of the version to be published, and agree to be accountable for all aspects of the work. 


\section{Disclosure}

The authors report no conflicts of interest in this work.

\section{References}

1. Brown MT, Bussel JK. Medication adherence: who cares? Mayo Clin Proc. 2011;86(4):304-314. doi:10.4065/mcp.2010.05753.

2. Brazil. Ministry of Health. Secretariat of Science, Technology and Strategic Inputs. 2nd ed. Brasília: Department of pharmaceutical care; 2010:1135 p. il (Series B. Basic Texts of Health).

3. Menditto E, Cahir C, Aza-Pascual-Salcedo M, et al. Adherence to chronic medication in older populations: application of a common protocol among three European cohorts. Patient Prefer Adherence. 2018;12:1975-1978.

4. Mukete BN, Ferdinand KC. Polypharmacy in older adults with hypertension: A comprehensive review. J Clin Hypertens. 2016;18 (1):10-18. doi:10.111/jch.12624.

5. IBGE. Instituto Brasileiro de Geografia e Estatística. Projeção da população do Brasil por sexo e idade para o período 1980-2060. 2013. Avaialble from: ftp://ftp.ibge.gov.br/Projecao_da_Populacao/Projecao_ da_Populacao_2013/nota_metodologica_2013.pdf. Accessed September 9, 2019.

6. WHO. World report on aged and health. 2015. Avaialble from: https://apps.who.int/iris/bitstream/handle/1 0665/186463/ 9789240694811_eng.pdf?sequence=1. Accessed September 9, 2019.

7. Tavares NUL, Bertoldi AD, Thumé E, Facchini LA, de França GVA, Mengue SS. Factors associated with low adherence to medication in older adults. Rev Saude Publica. 2013;47(6):1092-1101.

8. WHO, Drug C for SM. ATC (Anatomical Therapeutic Chemical). 2018. Available from: https://www.whocc.no/atc_ddd_index/. Accessed September 9, 2019.

9. Uchmanowicz B, Chudiak A, Uchamanowicz I, Rosinkzuc J, Froelicher E. Factor influencing adherence to treatment in older adults with hypertension. Clin Interv Aging. 2018;13:2441-2445.

10. Ragbaoui Y, Nouamou I, Hammri AE, Habbal R. Predictive factors of medication adherence in patients with chronic heart failure: morocco's experience. Pan Afr Med J. 2017;26(2):115. doi:10.11604/ pamj.2017.26.115.11471.

11. Morisky DE, Green LW, Levine DM. Concurrent and predictive validity of a self-reported measure of medication adherence. Med Care. 1986;24(1):67-74.7.

12. WHO. Adherence to long-term therapies: evidence for action. 2003. Available from: https://www.who.int/chp/knowledge/publications/ adherence_report/en/. Accessed September 9, 2019.

13. Eid L, Nogueira M, Veiga EV, Cesarino E, Alves LM. Adesão ao tratamento anti-hipertensivo: análise pelo Teste de Morisky-Green. Rev Eletrônica Enferm. 2013;15(2):362-367. doi:10.5216/ree.v15i2.15599

14. Ben A, Neumann C, Mengue S The Brief Medication Questionnaire and Morisky-Green test to evalute medication adherence [Teste de MoriskyGreen e Brief medication Questionnaire para avaliar adesão a medicamentos]. Rev Saúde Pública. 2012;46(2):279-289. PIMD: 2233118.

15. Costa FA, Silvestre L, Periquito C, et al. Drug-related problems identified in a sample of portuguese institutionalised elderly patients and pharmacists' interventions to improve safety and effectiveness of medicines. Drugs Real World Outcomes. 2016;3(1):89-97. doi:10.1007/s40801-016-0061-x.

16. Masnoon N, Shakib S, Kalisch-Ellett L, Caughey GE. What is polypharmacy? A systematic review of definitions. BMC Geriatr. 2017;17 (1):230. doi:10.1186/s12877-017-0621-2

17. Thomazi R, Silveira LVA, Boas PJFV, Jacinto AF. Frequency of dementia among elderly admitted to a Geriatric Inpatient Sector of a Brazilian public hospital. Dement Neuropsychol. 2018;12(1):35-39. doi:10.1590/1980-57642018dn12-010005.
18. Engedal K, Lacks J. Towards a Brazilian dementia plan? Lessons to be learned from Europe. Dement Neuropsychol. 2016;10(2):44-78. doi:10.1590/S1980-5764-2016DN1002002

19. Melo DM, Barbosa AJG. The use of the mini-mental state examination in research with elderly people in Brazil: a systematic review [O uso do mini-exame do estado mental em pesquisas com idosos no Brasil: uma revisão sistemática]. Ciên Saúde Colet. 2015;20 (12):3865-3876. doi:10.1590/1413-812320152012.06032015.

20. Santos GS, Olm Cunha ICK. Factors associated with the consumption of drugs among the elderly of a basic health unit [Fatores associados ao consumo de medicamentos entre idosos de uma unidade básica de saúde]. Rev Família Ciclos Vida E Saúde No Context Soc. 2017;5(2):191. doi:10.18554/refacs.v5i2.1709.

21. Aquino GA, da Cruz DT, Silvério MS, et al. Factors associated with adherence to pharmacological treatment in the elderly who use antihypertensive medication [Fatores associados à adesão ao tratamento farmacológico em idosos que utilizam medicamento anti-hipertensivo]. Rev Bras Geriatr Gerontol. 2017;20(1):116, 127. doi:10.1590/1981-22560170.160098.

22. Stopa SR, Cesar CLG, Segri NJ, Alves MCGP, Barros MBA, Goldbaum M. Prevalence of arterial hypertension, diabetes mellitus and adherence to behavioral measures in the city of São Paulo, Brazil, 2003-2015. Public Health Notebook. 2018;34(10):e00198717.

23. Hennein H, Heang SJ, AU R, et al. Barriers to medication adherence and links to cardiovascular disease risk factor control: the Framingham Study. Intern Med J. 2018;48(4):414-421. doi:10.111/imj13687.

24. Vieira LB, Helena S, Cassiani DB. Factors associated with adherence to pharmacological treatment in the elderly who use antihypertensive medication [Avaliação da Adesão Medicamentosa de Pacientes Idosos Hipertensos em Uso de Polifarmácia]. Rev Bras Cardiol. 2014;27 (3):195-202.

25. Lee GKY, Wang HHX, Liu KQL, Cheung Y, Morisky DE. Determinants of medication adherence to antihypertensive medications among a Chinese population using morisky medication adherence scale. PLoS One. 2013;8(4):e62775. doi:10.1371/journal. pone. 0062775

26. Meneses A, Sá M. Pharmaceutical assistance to the elderly, fundamentals and proposals [Assistência farmacêutica ao idoso, fundamentos e propostas]. Rev Geriatr Gerontol. 2010;3(4):151-154.

27. Iquize R, Theodoro F, Carvalho K, Oliveira M, Barros J, Silva A. Educational practices of the diabetic patient and perspective of the health professional. A systematic review [Práticas educativas do paciente diabético e perspectiva do profissional de saúde. Uma revisão sistemática]. $J$ Bras Nefrol. 2017;39(2):196-204. doi:10.5935/0101-2800.20170034.

28. Ramos LR, Tavares NUL, Bertoldi AD, et al. Polypharmacy and polymorbidity in older adults in Brazil: a public health challenge. Rev Saude Publica. 2016;50(Suppl 2):1-13. doi:10.1590/S15188787.2016050006145.

29. Goulart LS, Carvalho AC, Lima JC, Pedrosa JM, Lemos PL, Oliveira RB. Consumption of medications for the elderly from a basic health unit of Rondonópolis/MT [Consumo de Medicamentos por idosos de uma unidade básica de saúde de Rondonópolis/MT]. Estud Interdiscipl Envelhec. 2014;19(1):79-94.

30. Elliott RA, Booth JC. Problems with medicine use in older Australians: a review of recent literature. J Pharm Pract Res. 2014;44(4):258-271. doi:10.1002/jppr.1041.

31. Yap AF, Thirumoorthy T, Kwan YH. Medication adherence in the elderly. J Clin Gerontol Geriatr. 2016;7(2):64-67. doi:10.1016/j. jcgg.2015.05.001.

32. Romskaug R, Molden E, Straand J, et al. Cooperation between geriatricians and general practitioners for improved pharmacotherapy in home-dwelling elderly people receiving polypharmacy - the COOP Study: study protocol for a cluster randomised controlled trial. Trials. 2017;18(1):1-9. doi:10.1186/s13063-017-1900-0. 
33. Park HY, Seo SA, Yoo H, Lee K. Medication adherence and beliefs about medication in elderly patients living alone with chronic diseases. Patient Prefer Adherence. 2018;12:175-181. doi:10.2147/PPA. S151263.

34. Lea SC, Watts KL, Davis NA, et al. The potential clinical benefits of medicines optimisation through comprehensive geriatric assessment, carried out by secondary care geriatricians, in a general practice care setting in North Staffordshire, UK: a feasibility study. BMJ Open. 2017;7(9):1-7. doi:10.1136/bmjopen-2016-015278.
35. Kassavou A, Sutton S. Reasons for non-adherence to cardiometabolic medications, and acceptability of an interactive voice response intervention in patients with hypertension and type 2 diabetes in primary care: A qualitative study. BMJ Open. 2017;7(8):e015597. doi:10.1136/bmjopen-2016-015597.

36. Andrews AM, Russel CL, Cheng AL. Medication adherence and interventions for olders adults with heart failure: a systematic review. J Gerontol Nurs. 2017;43(10):37-45. doi:10.3928/ 00989134-20170523-01.

\section{Publish your work in this journal}

Patient Preference and Adherence is an international, peer-reviewed, open access journal that focusing on the growing importance of patient preference and adherence throughout the therapeutic continuum. Patient satisfaction, acceptability, quality of life, compliance, persistence and their role in developing new therapeutic modalities and compounds to optimize clinical outcomes for existing disease states are major areas of interest for the journal. This journal has been accepted for indexing on PubMed Central. The manuscript management system is completely online and includes a very quick and fair peer-review system, which is all easy to use. Visit http:// www.dovepress.com/testimonials.php to read real quotes from published authors. 